\title{
An external quality assessment scheme in histopathology
}

\author{
ANTHEA J SHERWOOD, A C HUNT \\ From the Departments of Histopathology, Torbay Hospital, Torquay, and Plymouth General Hospital, \\ Derriford Road, Plymouth
}

SUMMARY The details of an external quality assessment scheme in histopathology based on district general hospitals in south west England are described. The scheme is supplementary to internal audit carried out in individual departments.

In 1981 Whitehead and Woodford ${ }^{1}$ defined an external quality assessment scheme (EQAS) as "a system of objectively checking laboratory results by means of an external agency" and said that it included "comparison of a laboratory's results ... with those of other laboratories." In this paper we report the details of a scheme which we believe to be the first working EQAS in diagnostic histopathology in the United Kingdom and present some of our results. The scheme is based on small group circulation somewhat similar to, but simpler than, that available in a few topics from the College of American Pathologists ${ }^{2} 3$ and is designed to monitor routine reporting in the histopathology laboratory.

\section{Outline of scheme}

Up to 11 consultant histopathologists from six district general hospitals in the far south west of England are taking part in this scheme. The group was already meeting twice a year as an informal slide club. One of us (AJS) is the coordinator.

For each circulation of the scheme, each hospital is asked to submit seven haematoxylin and eosin stained sections from all the blocks taken from the first two examples of a type of specimen (as selected by the coordinator) received in their laboratory after a specific date together with the clinical details as given on the original request form, the gross descriptions, and the microscopical reports as sent to the clinicians. These cases are allotted an accession number by reference to a table of random numbers in such a way that the persistently late submitters are not always the last numbers of a series and so that cases have no tendency to appear in pairs. Report forms are prepared by the

Accepted for publication 15 December 1983 coordinator and are sent, with the slides of all cases submitted, to each hospital, which is identified by a code number. Where there are two or more consultants in a laboratory the material is sent to one and he or she is asked to photocopy the forms and circulate the slides. Each consultant is expected to report the cases as if they were routine material and to return the forms to the coordinator, keeping a copy and the slides for future reference. The results are collated in such a way that one sheet of paper will show all the reports on one particular case (Figure). The order is determined in a random fashion so that consultant A's findings will not necessarily be first or, indeed, in any other specific position on the list. The coordinator also prepares summary charts (Tables 1 and 2) and calculates the degree of consensus as to whether a lesion is benign or malignant and to which category of disease it belongs. Obviously the column headings vary with the nature of the tissue under discussion. The disease classification is assessed and allotted by the coordinator from the free form written reports given by the participants. Copies of the collated report forms and summary charts are circulated to each hospital so that the consultants concerned can compare their reports with the others.

Cases in which consensus has not been reached are discussed at the slide club meetings, together with any interesting or difficult problems. If agreement has still not been reached the case may be referred to an acknowledged expert outside the group.

\section{Results}

So far we have completed seven rounds and four others are in progress. We have examined the practical aspects of the scheme and assessed its acceptability to our colleagues. 
HISTOPATHOLOGY SELF-AUDIT SCHEME (SOUTH-WEST)

COLLATED REPORTS

CASE CODE 9999

CLINICAL DETAILS A 43 year old man with three months diarrhoea now improving.
BLOCKS

GROSS DESCRIPTION A mucosal biopsy $0.3 \mathrm{~cm}$ diameter.

HISTOLOGY

Normal rectal mucosa.

A low grade non-specific proctitis with no evidence of active ulcerative colitis.

Rectal mucosa within normal limits.

There is a mild increase in non-specific chronic inflammatory cells in the lamina propria but no specific features.

A resolving mild proctitis.

Minor chronic inflammation only with no goblet cell depletion or crypt distortion. (There is no evidence of active disease here.)

Rectal mucosa showing no significant abnormality.

Non-specific mild mucosal inflammation with retention of goblet cells. There are no specific features.

Sample report form.

Table 1 Summary of macroscopical findings: hysterectomy specimen

\begin{tabular}{|c|c|c|c|c|c|c|c|c|c|c|c|c|c|c|c|}
\hline \multirow{2}{*}{$\begin{array}{l}\text { Case } \\
\text { no }\end{array}$} & \multirow{2}{*}{$\begin{array}{l}\text { Size } \\
\text { stated }\end{array}$} & \multirow{2}{*}{$\begin{array}{l}\text { Weight } \\
\text { given }\end{array}$} & \multicolumn{3}{|l|}{ Fibroids } & \multicolumn{3}{|l|}{ Ovaries } & \multicolumn{3}{|l|}{ Other } & \multicolumn{4}{|c|}{ Blocks } \\
\hline & & & Present & Size & App & Present & Size & $A p p$ & Present & Size & App & Endo & $C x$ & $\begin{array}{l}\text { Fibr/ } \\
\text { myo }\end{array}$ & $\begin{array}{l}\text { Ovaries } \\
\text { and ot }\end{array}$ \\
\hline $\begin{array}{l}1 \\
2 \\
3 \\
4 \\
5\end{array}$ & $\begin{array}{l}\mathbf{Y} \\
\mathbf{Y} \\
\mathbf{Y} \\
\mathbf{N} \\
\mathbf{Y}\end{array}$ & $\begin{array}{l}\mathbf{N} \\
\mathbf{Y} \\
\mathbf{N} \\
\mathbf{Y} \\
\mathbf{Y}\end{array}$ & $\begin{array}{l}\mathbf{Y} \\
\mathbf{N} \\
\mathbf{N} \\
\mathbf{Y} \\
\mathbf{N}\end{array}$ & $\frac{\mathrm{Y}}{\overline{\mathrm{N}}}$ & $\frac{\bar{Z}}{\overline{\mathrm{N}}}$ & $\begin{array}{l}\mathbf{N} \\
\mathbf{Y} \\
\mathrm{N} \\
\mathrm{Y} \\
\mathrm{Y}\end{array}$ & $\frac{\bar{Y}}{\bar{N}} \frac{}{N}$ & $\begin{array}{l}\bar{N} \\
\mathrm{Y} \\
\mathrm{Y}\end{array}$ & $\begin{array}{l}\mathbf{N} \\
\mathbf{N} \\
\mathbf{N} \\
\mathbf{N} \\
\text { Cyst in } \\
\text { broad } \\
\text { ligament }\end{array}$ & $\begin{array}{l}\bar{Z} \\
\bar{Y}\end{array}$ & $\begin{array}{l}\bar{E} \\
\bar{Y}\end{array}$ & $\begin{array}{l}1 \\
2 \\
1 \\
1 \\
1\end{array}$ & $\begin{array}{l}1 \\
1 \\
1 \\
2 \\
1\end{array}$ & $\frac{1}{\frac{2}{-}}$ & 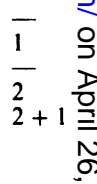 \\
\hline $\begin{array}{r}6 \\
7 \\
8 \\
9 \\
10 \\
11 \\
12\end{array}$ & $\begin{array}{l}\mathbf{N} \\
\mathbf{Y} \\
\mathbf{Y} \\
\mathbf{N} \\
\mathbf{N} \\
\mathbf{Y} \\
\mathbf{Y}\end{array}$ & $\begin{array}{l}\mathbf{Y} \\
\mathbf{Y} \\
\mathbf{N} \\
\mathbf{Y} \\
\mathbf{Y} \\
\mathbf{Y} \\
\mathbf{N}\end{array}$ & $\begin{array}{l}\mathbf{Y} \\
\mathbf{N} \\
\mathbf{Y} \\
\mathbf{Y} \\
\mathbf{N} \\
\mathbf{N} \\
\mathbf{Y}\end{array}$ & $\begin{array}{l}\frac{\mathrm{Y}}{\mathrm{Y}} \\
\mathrm{N} \\
\frac{\mathrm{Y}}{\mathrm{Y}}\end{array}$ & $\begin{array}{l}\frac{Y}{N} \\
\frac{N}{N}\end{array}$ & $\begin{array}{l}\mathbf{N} \\
\mathbf{N} \\
\mathbf{N} \\
\mathbf{Y} \\
\mathbf{Y} \\
\mathbf{N} \\
\mathbf{Y}\end{array}$ & $\begin{array}{l}\overline{-} \\
\bar{N} \\
\frac{N}{Y}\end{array}$ & $\begin{array}{l}\overline{-} \\
\overline{\bar{N}} \\
\mathrm{Y} \\
\frac{\mathrm{Y}}{\mathrm{Y}}\end{array}$ & $\begin{array}{l}\mathbf{N} \\
\mathbf{N} \\
\mathbf{N} \\
\mathbf{N} \\
\mathbf{N} \\
\mathbf{N} \\
\text { Mass in } \\
\text { fallopian } \\
\text { tube }\end{array}$ & $\begin{array}{l}\bar{z} \\
\bar{z} \\
\bar{Y}\end{array}$ & $\begin{array}{l}\bar{z} \\
\bar{E} \\
\bar{Y}\end{array}$ & $\begin{array}{l}1 \\
1 \\
1 \\
1 \\
1 \\
2 \\
1\end{array}$ & $\begin{array}{l}1 \\
2 \\
1 \\
2 \\
1 \\
1 \\
1\end{array}$ & $\begin{array}{l}\frac{2}{1} \\
\frac{2}{-} \\
\frac{1}{1}\end{array}$ & 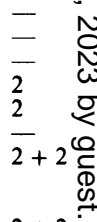 \\
\hline Total & $8 / 12$ & $8 / 12$ & $6 / 12$ & $4 / 6$ & $1 / 6$ & $6 / 12$ & $2 / 6$ & $4 / 6$ & $2 / 12$ & $2 / 12$ & $2 / 12$ & 14 & 14 & 9 & $2+2 \tau$ \\
\hline $\begin{array}{l}\text { Y } \\
\text { N } \\
\text { App } \\
\text { Endo } \\
\text { Cx } \\
\text { Fibr/my }\end{array}$ & $\begin{aligned} & =\text { yes } \\
& =\text { no } \\
& =\text { no } \\
& =\mathrm{ap} \\
& =\mathrm{en} \\
& =\mathrm{cer} \\
\text { yo } & =\mathrm{fib}\end{aligned}$ & $\begin{array}{l}\text {-that is, } \\
\text {-that is, } \\
\text { applicab } \\
\text { earances } \\
\text { ometriun } \\
\text { ix. } \\
\text { oids/myo }\end{array}$ & $\begin{array}{l}\text { that para } \\
\text { not ment } \\
\text { le. } \\
\text { n. }\end{array}$ & $\begin{array}{l}\text { meter } \\
\text { oned. }\end{array}$ & sured & feature de & scribe & & & & & & & & 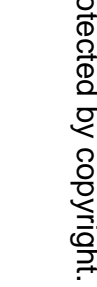 \\
\hline
\end{tabular}


Table 2 Summary of microscopical findings: prostatic curettings

\begin{tabular}{|c|c|c|c|c|c|c|c|c|c|c|c|}
\hline \multirow{3}{*}{$\begin{array}{l}\text { Case } \\
\text { no }\end{array}$} & \multicolumn{4}{|c|}{ Malignant } & \multirow{3}{*}{$\begin{array}{l}\text { * Border } \\
\quad \text { line }\end{array}$} & \multirow{2}{*}{\multicolumn{3}{|c|}{$\frac{\text { Benign }}{\text { Inflammation }}$}} & \multirow{3}{*}{$\begin{array}{l}\text { Nodular } \\
\text { hyperplasia }\end{array}$} & \multicolumn{2}{|l|}{ Consensus } \\
\hline & \multicolumn{3}{|c|}{ Differentiation } & \multirow[t]{2}{*}{ Not stated } & & & & & & \multirow{2}{*}{$\begin{array}{l}\text { Ben v } \\
\text { Mal }(\%)\end{array}$} & \multirow{2}{*}{$\begin{array}{l}\text { Category } \\
(\%)\end{array}$} \\
\hline & Poor & Average & Good & & & Acute & Chronic & $\begin{array}{l}\text { Granulo- } \\
\text { matous }\end{array}$ & & & \\
\hline 901 & & & & & & & $++t$ & & $\begin{array}{l}\times \times \times \times \times \\
\times \times \times \times \times\end{array}$ & 100 & 100 \\
\hline 902 & & $x \times \times \times x$ & $x \times x$ & $x \times$ & & & & & กลก & 100 & 50 \\
\hline 903 & & & & & ++ & & & & $\begin{array}{l}\times \times \times \times \times \\
\times \times \times \times \times\end{array}$ & 100 & 100 \\
\hline 904 & & & $x$ & & & & & $\begin{array}{l}\times \times \times \times \times \\
\times \times \times \times\end{array}$ & & 90 & 90 \\
\hline 905 & & & & & & & & & $\begin{array}{l}\times \times \times \times \times \\
\times \times \times \times \times\end{array}$ & 100 & 100 \\
\hline 906 & & & & & & $++t$ & & & $\begin{array}{l}\times \times \times \times \times \\
\times \times \times \times \times\end{array}$ & 100 & 100 \\
\hline 907 & & & & & & & ++ & & $\begin{array}{l}\times \times \times \times \times \\
\times \times \times \times \times\end{array}$ & 100 & 100 \\
\hline 908 & & $\begin{array}{l}\times \times \times \times \times \\
\times \times \times\end{array}$ & $x$ & $x \times$ & & & & & & 100 & 70 \\
\hline 909 & & & & & & & & & $\begin{array}{l}\times \times \times \times \times \\
\times \times \times \times \times\end{array}$ & 100 & 100 \\
\hline 910 & & & & & & & & . & $\begin{array}{l}\times \times \times \times \times \\
\times \times \times \times \times\end{array}$ & 100 & 100 \\
\hline 911 & $x \times \times$ & $x \times x \times$ & & $x \times x$ & & & & & 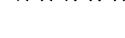 & 100 & 40 \\
\hline 912 & & & & & & & & & $\begin{array}{l}\times \times \times \times \times \\
\times \times \times \times \times\end{array}$ & 100 & 100 \\
\hline
\end{tabular}

*An entry in this column usually indicates that the pathologist was concerned about a small area in an otherwise benign biopsy.

$x=$ main diagnosis.

$+\quad=$ subsidiary diagnosis

Ben $=$ benign

Mal = malignant .

Table 3 Details of material received

\begin{tabular}{llccc}
\hline Nature of tissue & Cases submitted & Blocks & Slides submitted & Reports received \\
\hline Prostatic curettings & 10 & 28 & 196 & 90 \\
Lymph node biopsy samples & 10 & 11 & 77 & 90 \\
Rectal biopsy samples & 12 & 12 & 84 & 120 \\
Salivary glands & 10 & 21 & 147 & 100 \\
Thyroids & 12 & 28 & 196 & 108 \\
Colectomy specimens & 6 & 50 & 350 & 96 \\
Testicular masses & 12 & 184 & 1,288 & 652 \\
Total & 72 & & & \\
\hline
\end{tabular}

\section{MATERIAL SUBMITTED}

Some relevant details concerning the nature of tissues requested and the slides and reports received are summarised in Table 3. The number of consultants participating in any one round varied from eight to 10 . Most tissues examined were suitable, although some difficulties were encountered with small endoscopic biopsy samples because the blocks had been largely cut through at the time of the original examination. This was particularly true of gastric biopsy samples and has resulted in an amendment to the protocol (participants are now asked to ensure that the lesion present in the original microscopical report is present in all slides submitted to the scheme).

Not all departments could provide clinical details of the type written on the request form. This seemed to be related to the practice of using separate request and report forms and discarding the former. In some types of specimen it is necessary to include the date of biopsy in order to complete the clinical details; this point was overlooked in our endometrial curettage series.

\section{COLLATION OF REPORTS \\ Gross descriptions}

The summary charts show how many hospitals included details such as weight, colour, and size of specimen in the gross description of a particular type of specimen. It is also possible to compare the numbers of blocks taken by different pathologists and thus 
Table 4 Estimate of range of sampling

\begin{tabular}{|c|c|c|c|c|c|c|}
\hline & \multicolumn{3}{|c|}{ Blocks/log of wet tissue } & \multicolumn{3}{|c|}{ Blocks/cm diameter of tumour } \\
\hline & Mean & Range & No & Mean & Range & No \\
\hline $\begin{array}{l}\text { Prostatic curettings } \\
\text { Thyroids } \\
\text { Colectomy specimens } \\
\text { Testicular masses }\end{array}$ & $\begin{array}{r}5 \\
0 \cdot 6 \\
\text { NA } \\
\text { NA }\end{array}$ & $\begin{array}{l}0.6-10 \\
0 \cdot 15-2\end{array}$ & $\begin{array}{l}10 \\
10\end{array}$ & $\begin{array}{l}\text { NA } \\
0.88 \\
0.55 \\
0.87\end{array}$ & $\begin{array}{l}\text { NA } \\
0 \cdot 37-2 \cdot 8 \\
0 \cdot 29-1 \cdot 5 \\
0 \cdot 5-1 \cdot 75\end{array}$ & $\begin{array}{l}6 \\
6 \\
6\end{array}$ \\
\hline
\end{tabular}

NA $=$ Not applicable.

This calculation could not be performed on all specimens either through lack of information or because it was unsuitable.

Table 5 Consensus of histological opinion

\begin{tabular}{|c|c|c|c|c|c|c|c|c|c|}
\hline & \multicolumn{4}{|c|}{ Benign $v$ malignant } & \multicolumn{4}{|c|}{ Calegory of disease } & \multirow{3}{*}{$\begin{array}{l}\text { Total } \\
\text { cases }\end{array}$} \\
\hline & \multicolumn{4}{|c|}{ No of cases showing } & \multicolumn{4}{|c|}{ No of cases showing } & \\
\hline & $\begin{array}{l}\text { Full } \\
\text { agreement }\end{array}$ & l diss & 2 diss & $\begin{array}{l}3 \text { or } 4 \\
\text { diss }\end{array}$ & $\begin{array}{l}\text { Full } \\
\text { agreement }\end{array}$ & I diss & 2 diss & $\begin{array}{l}3 \text { or more } \\
\text { diss }\end{array}$ & \\
\hline Prostatic curettings & 10 & 0 & 0 & 0 & 6 & 1 & 1 & 2 & 10 \\
\hline Lymph node biopsy samples & 10 & 0 & 0 & 0 & 2 & 1 & 3 & 4 & 10 \\
\hline Rectal biopsy samples & 11 & 0 & 0 & 1 & 1 & 2 & 4 & 5 & 12 \\
\hline Salivary glands & 8 & 2 & 0 & 0 & 6 & 4 & 0 & 0 & 10 \\
\hline Thyroidectomy specimens & 11 & 0 & 1 & 0 & 7 & 0 & 2 & 3 & 12 \\
\hline Testicular masses & 1 & 0 & 0 & 0 & 6 & 3 & 2 & 1 & 12 \\
\hline Total $(\%)$ & $62(93.9)$ & $2(3 \cdot 0)$ & $1(1 \cdot 5)$ & $1(1 \cdot 5)$ & $28(42 \cdot 4)$ & $11(16 \cdot 7)$ & $12(18 \cdot 2)$ & $15(22 \cdot 7)$ & 66 \\
\hline
\end{tabular}

Examine the extent of sampling. Not surprisingly, we found considerable variations in both these aspects of reporting practice among the group (Table 4). Some, but not all, of this variation was due to the differing degrees of difficulty of the specimens concerned.

Discussions at the slide club meetings indicated that participants did not consider the gross descriptions and details of sampling to be a particularly important part of the survey. Generally speaking, they thought that the appropriate blocks were taken and that the existing guidelines-such as those of Rosai ${ }^{4}$-were largely impractical for routine reporting in district general hospitals.

\section{Microscopical reports}

Of the 66 cases requiring a decision as to whether or not malignancy was present, full consensus was achieved in $62(93.9 \%)$. In two cases one person disagreed with the majority, in another there were two dissenters, and in the fourth there was no clear consensus as to whether the lesion could safely be diagnosed as a malignant condition. This last case was referred to an expert outside the region and his report was then circulated to all participants. When we consider the categories of disease there is, as one might expect, a lesser degree of consensus. Table 5 shows the extent of agreement reached in the different tissues examined. As might be expected, the greatest degree of consensus was achieved with specimens such as salivary glands and the least with the rectal and lymph node biopsy samples.

A simple count of the numbers of reports varying from the diagnosis favoured by most consultants gives a rate of discrepancy of $31.6 \%$ of all reports. If, however, we consider those cases $(77 \cdot 3 \%)$ where only one or two consultants disagreed with their colleagues then the discrepancy rate improves and is reduced to $7 \cdot 5 \%$. This rate is probably distorted by the fact that the coordinator has to assign each free form report to an appropriate disease category, a process involving interpretation and judgment. We consider this process to be valid to some extent as it resembles the clinicians' reading of a report. Some of the distinctions between disease categories may not be importantsuch as the degree of differentiation of tumour in a rectal biopsy ${ }^{5}$ - whereas others - such as the distinction between ulcerative colitis and Crohn's disease-are more important. Furthermore, the rate of discrepancy is a crude calculation. We hope to be able to improve the analysis in future reports when more information is available.

\section{RESOURCE REQUIREMENTS}

As well as the obvious requirements of slides, stationery, postage, and so on, the most expensive part of the scheme is probably the consultant, medical labo- 0 ratory scientific officer, and secretarial time concerned. Each circulation requires about 1-2 h of consultant time from each participant for the selection and reporting of cases. The preparation and packaging of the slides to be submitted takes about $2 \mathrm{~h}$ for each hospital. The coordinator spends at least another $10 \mathrm{~h}$ for each circulation in administration and in telephoning colleagues to chase up reports submitted 
late. In addition, the secretarial and technical staff in the coordinator's department contribute another $12 \mathrm{~h}$ for each circulation. We intend to reduce this $22 \mathrm{~h}$ of coordinating time considerably by using a microcomputer to perform the routine clerical work and the random allocations.

\section{ACCEPTABILITY}

This has been assessed during the course of discussions at slide meetings and by telephone conversations. The fact that a consensus can be achieved seems to have made the scheme more acceptable and to have reduced the initial consumer resistance. Some participators have difficulty in finding enough time to report a complete series of slides in one session. As a result they give them less time than would be devoted to routine material. Because one set of all slides submitted is sent to each participant, however, they receive their own material for reporting. When we have accumulated sufficient data we hope to assess whether reporting for the scheme is significantly different from routine reporting.

The lack of special stains provoked some consultants into making appropriate comments in their reports such as "Would do special stains and immuno-histology." This may provide others with cause for thought and certainly leads to discussions at slide club meetings.

We have found that the momentum of the scheme and the level of interest are best maintained if the coordinator rings the participants regularly when reports are outstanding. Some delays were due to the requirement for the slide to be circulated among the pathologists in any one hospital. We are therefore now sending one set to each consultant in order to reduce delays.

\section{Discussion}

In the United Kingdom there has been much reluctance on the part of histopathologists to accept any form of "quality control" of professional opinion. Even if anonymity is preserved, many histopathologists think that periodical testing of their knowledge with sets of spot slides which would include unusual or difficult cases is unrealistic. As a colleague said, "It would be like retaking the MRCPath practical every month." Schemes for the circulation of sets of test spot slides have been proposed. The most notable example is the Australian study. ${ }^{2}$ This does not use consensus diagnosis but "correct" answers made by acknowledged experts. The participants' reports are compared with the correct diagnosis. We chose not to adopt such a scheme because it was in some respects not a true EQAS as defined by Whitehead and Woodford ${ }^{1}$ and because it would impose many practical difficulties in providing a continuous supply of new material and of generally acceptable expert diagnoses, particularly if it were to be adopted on a national basis.

The circulation of such spot slides is little different from the participation of the pathologist in seminars and slide clubs. In 1983 the Histopathology Advisory Committee of the Royal College of Pathologists recommended to the membership of the college that slide clubs should be set up as a means of encouraging quality assurance and medical audit in histopathology. ${ }^{6}$ This proposal has already been criticised for being somewhat limited in its outlook. ${ }^{7}$ The EQAS outlined in this paper involves a slide club of the type recommended by the college. Such slide clubs could run an individual similar scheme or, preferably, each could operate as a cell within a regional or national system. It is a relatively simple EQAS and could be run by someone lacking specialist knowledge. It could be entirely independent of slide clubs, which would be advantageous in that regular changes in the membership of the individual groups would be possible, although there would be less opportunity for informal discussion. The scheme allows a pathologist to compare his histological reporting style and diagnoses with those of his colleagues. The variability and the extent of usage of grading systems, subdivisions, and qualifications of main diagnoses can also be examined. It is therefore similar to, but simpler than, the early College of American Pathologists peer group EQAS. The American scheme now entails the computer marking of fill in questionnaires and a complex central data bank. Having shown that consensus diagnoses by peer groups of routine pathologists are similar to diagnoses made by groups of experts in that particular field, as well as having built up a considerable store of submitted material, the College of American Pathologists intends to expand its scheme to a "dual track educational and quality assurance program."

Our more modest scheme does have some advantages. Because the original gross descriptions of the relevant specimens are submitted, their complexity and the extent of tissue sampling can be compared by the participating consultants and differences in methods brought to their attention. Similarly laboratory staff can compare standards of technical preparation. The numbers involved are smaller than the larger studies concerning mastectomy specimens or reporting practice in large bowel cancer, ${ }^{9}$ but, nevertheless, our scheme does serve to indicate to individuals the ways in which their methods and findings differ from those of their colleagues. The differences found are similar to those shown in the large single organ studies. So far we have chosen to use a different tissue for each circulation. We shall repeat some of these, partly 
to see if reporting practice has changed and partly to increase the data base.

In considering external assessment in histopathology, Langley ${ }^{3}$ stated ". . . In practice, the slides are examined with unusual care and with the use of books." We hope to be able to assess this when we have amassed sufficient data to be able to compare the original microscopical reports with those written for the scheme. So far discussions indicate that the reverse is true and that the slides for the scheme tend to be reported in the odd few minutes in a hurried fashion. This probably reflects the fact that each of the pathologists concerned works at a rate above that recommended by the Royal College of Pathologists and provides further support for the hypothesis that there would have to be a change in the profession's attitudes for EQAS to be generally acceptable.

Some of the ways in which we would like to develop the scheme have already been mentioned and will be described in future reports. We anticipate that EQAS in histopathology will supplement both internal (intradepartmental) audit, whether informal or the more formal schemes already described by others, ${ }^{1011}$ and the educational programmes, with their slide seminars, as sponsored by the various learned societies. Our scheme could be adapted by using questionnaires rather than free form reports as a tool for the formal statistical analysis of the repeatability of histological grading systems and of interobserver variability in the fashion recommended by Silcocks. ${ }^{12}$ It would then be similar to studies performed by others ${ }^{1314}$ which amply show that pathologists differ, but would no longer be an EQAS testing the free form reports as the clinician actually receives them. Such an adaptation would therefore negate the purpose of the scheme, which is to provide the histopathologist with an outside agency by which he can assess his own performance in his routine duties.
We thank all those consultants who have taken part in the scheme for their support. We are most grateful to all the laboratory and secretarial personnel concerned, particularly to Mrs PM Skene for all her assistance, not least in the typing of this manuscript.

\section{References}

${ }^{1}$ Whitehead TP, Woodford FP. External quality assessment of clinical laboratories in the United Kingdom. J Clin Pathol 1981;34:947-57.

${ }^{2}$ Penner DW. Quality control and quality evaluation in histopathology and cytology. Pathology Annual 1973;8:1-19.

${ }^{3}$ Derman H. Histopathology reporting in large bowel cancer. $\mathrm{Br}$ Med J 1982;284:346.

${ }^{4}$ Rosai J. Ackerman's surgical pathology, 6th ed. St Louis: CV Mosby Company, 1981:A1-97.

${ }^{5}$ Silcocks P. Observer variation in histological diagnosis. $J$ Clin Pathol 1983;36:1083.

${ }^{6}$ Bulletin of the Royal College of Pathologists April 1983;42:9.

${ }^{7}$ Morson BC. Quality assurance and medical audit in histopathology. J Clin Pathol 1983;36:1202.

${ }^{8}$ Van der Walt JD, Baithun Sia, Berry CL. Histopathology reporting of mastectomy specimens-an assessment of inter-hospital variation. J Clin Pathol 1983;36:1276-80.

${ }^{9}$ Blenkinsopp WK, Stewart-Brown S, Blesovsky L, Kearny G. Histopathology reporting in large bowel cancer. J Clin Pathol 1981;34:509-13.

${ }^{10}$ Owen DA, Tighe JR. Quality evaluation in histopathology 1975. Br Med J 1975; i:149-50.

${ }^{11}$ Frei JV, Morson BC. Medical audit of rectal biopsy diagnosis of inflammatory bowel disease. J Clin Pathol 1982;35:341-4.

${ }^{12}$ Silcocks PBS. Measuring repeatability and validity of histological diagnosis-a brief review with some practical examples. J Clin Pathol 1983;36:1269-75.

${ }^{13}$ Thomas GDM, Dixon MF, Smeeton NC, Williams NS. Observer variation in the histological grading of rectal carcinoma. J Clin Pathol 1983;36:385-91.

${ }^{14}$ Holman CDJ, James IR, Heenan PJ, et al. An improved method of analysis of observer variation between pathologists. Histopathology 1982;6:581-9.

Requests for reprints to: Dr Anthea J Sherwood, Department of Histopathology, Torbay Hospital, Torquay, Devon, TQ2 7AA, England. 